\title{
Attitude of School Community towards the use of Sign Language for Instructional Purpose
}

\author{
Wondwosen Mitiku, Bizuhan Balew \\ University of Gondar, College of Education \\ Department of Special Needs and Inclusive Education \\ Gondar, Ethiopia
}

DOI: $10.37648 / \mathrm{ijrssh} . v 10 \mathrm{i} 04.008$

Received:1 $1^{\text {th }}$ March, 2020; Accepted:29th March, 2020; Published:14th October, 2020

\begin{abstract}
This study is conducted in order to assess the attitude of school community towards the use of sign language for instructional purpose in Bahir Dar town in the case of Yekatit 23 and Donaber primary school. In order to attain the objectives of the study, related literatures about sign language and challenges related to the use of sign language was reviewed in detail. The study used descriptive survey as a research design to explain the current trends existing in the study area. As to the samples considered for the study, because there are only two schools it appeared manageable to take them as they are. In regards to participants of the study eighty seven participants, namely 4 from the school's principals, 7 from the professional teachers in special needs, 23 regular class teachers, 13 students with hearing impairments,and 44 students without hearing impairments were involved as sample participants. With regard to data gathering instrument, questionnaire, structured interview and observation were used to collect data from the participants. The finding shows that even though teachers have positive attitude to use sign language for media of instruction, they faced many challenges and the major barriers in teachings students with hearing impairments are lack of sign language skill, lack of appropriate training and lack knowledge and experience about teaching in integrated classes. Generally the researcher suggested that policy makers and official must give priority for child's primary language. This study also confirmed that students and teachers face challenges like mismatched teacher student ratio in the classroom and the shortage of material to teach sign language as a medium of instruction.

Key words: Sign language, Inclusive Education, Attitude, Ethiopia
\end{abstract}

From ancient times up to the Middle Ages, history records very little acceptance of deaf persons as a rightful members of society. Because of their in ability to speak and to use the language common to the general culture in which they lived, deaf persons were considered to be un able to learn, and they were regarded, for all practical purposes, as mentally handicapped
(McAnally Rose \&Quigly, 1994).Such understanding of disability is sometimes described as traditional model, which is a construct created by religion and culture in society (Colerdge, 1993 cited in Tirusew, 2005). 
As Tirusew (1998) indicated, communication problems can seriously interfere with interpersonal relationship for students with hearing impairment who receive all or part of their education in regular classrooms. Moors 1996 argued that the effects of hearing loss are pervasive and can create psychological stress. According to McAnally (1994), deaf children, compared with hearing children, have notable delays and substantial differences in the development of reading and writing skills.

Paul and Jackson (1993) maintained that differences in the cognitive performance of students who are deaf and of heir hearing peers are more due to inadequate development of conventional language system than to limited intellectual ability. Most probably, the limiting environment for interaction with one another may affect their intellectual ability as well as their social competence skills.

Tirusew (1998) asserted that it is not possible to make firm generalization about the way in which students who, are deaf and hard-of-hearing function academically. They do not perform as well as the hearing students on standardized tests of reading and writing, nevertheless, differences in language ability that result from deafness affect a student's ability to perform in traditional academic areas. The extent to which a child with hearing-impaired successfully interacts with family members, friends, and people in the community depends largely on the attitudes of other and the child's ability to communicate in some mutually accepted way. Regarding the attitude of societies towards people with hearing impaired, stated that hearing impaired is perceived as tragedy, a loss or a deficiency, and considered as Devine punishment for ancestral anger. Some also deny the abilities of the disabled (special need education 224 module, SNED 224)

Cultural diversity is a fact of life. This cultural diversity entails diversity in language use. Language is a system of symbols that people use for purposes of encoding and decoding information. The decoding and encoding of information can be done through an audio based symbol system i.e. spoken language or it can be done using a visual based symbol system that gives rise to written and sign language of the deaf..
From earlier recorded history gestures have been used for communication between groups of different languages and cultures. The use of formalized language of signs however has been gradual until the first attempt to educate deaf children was made. The public education of the hearing impaired using sign language began in France. In 1755 Abbe Charles de l' Epee founded the first public school for the deaf. He refined and developed the language of signs into a full language from which the present sign language are derived (Berker, 2011).

In most parts of the world especially developing countries, a number of deaf people have never been to school and are thus more or less illiterate. For educating the deaf people of these countries, the existence of sign language has been either ignored or repressed in many ways. The consequence is that deaf people are not aware of the rights they have in society; they live as a highly marginalized group in most developing countries.

They do not even know what is happening in their immediate society and the world at large. Moreover, prejudices and attitudes towards educating the deaf community and the value the deaf community retain for themselves have deeply influenced their living condition and chances of personal development. This is due to the fact that deaf people have not been educated in sign language. Improving the status of sign language has consequences for all areas of life for deaf people; it opens up possibilities for participation, information and influence and reduction of poverty (Journal of languages and culture Received 8 November, 2014)

Thus, the present study aimed at assessing theattitude of school community towards the use of sign language for instructional purpose in Bahir Dar town in the case of Yekatit 23 and Donaber primary school.

\section{STATEMENT OF THE PROBLEM}

Due to pedagogical, psychological, sociological and political opportunities, mother tongue education is accepted among many scholars. According to the Federal Democratic Republic of Ethiopia constitution, all nations, nationalities and peoples of Ethiopia are entitled to enjoy constitutionally guaranteed rights to free 
development of their cultures including the use of their languages. As the result, the ministry of education in the New Education and Training Policy of Ethiopia (1994) ensured to use mother tongue as a medium of instruction. The child's with hearing impaired language development is not expected to be developed as nonhearing child. Thus, mild to profound hearing impairment can be a barrier for language development. Teaching children with hearing impaired in segregated environment limits the interaction of students with hearing problems for their language development. Whereas the inclusive schooling creates good opportunities for children with hearing loss to interact without hearing loss students to develop their language skill (Davis, 2006)

According to Tirusew (2005), Teachers teaching in inclusive class room are not trained in sign language to facilitate the instruction students, with hearing impairment. Lack of sign language skill seriously challenges the instructional program for hearing impaired children in the regular schools. There are also prejudices and negative attitudes among the hearing community to ward educating the deaf community and undervaluing perceptions that the deaf community retains for themselves which deeply influenced the living conditions of deaf people and their chances of personal development in the country.

Therefore, so as to make the deaf community benefit from education as the hearing community dose, we need to incorporate into our research the accessibility of sign language education as a means of meaningful way of educating the deaf and able to bring to the public's attention to the social, cultural, economic and political benefit of it for the deaf community. Therefore this study aims to assess attitude of school community towards the use of sign language for instructional purpose in Yikatit 23 and Donaber primary schools based on the following research functions:

1. What is the attitude of students, teachers, and school principals towards the use of sign language for instructional purposes?

2. What are the challenges forstudents with hearing impaired regarding interaction with their teachers and hearing peers usingsign language for instructional purposes?

\section{General objective}

The general objective of this study is to assess attitude of school community towards the use of sign language for instructional purpose and the major problem student with hearing impairment face while practicing sign language for instructional purpose at Yekatit 23 and Donaberber primary school in Bahir Dar town.

\section{CHALLENGES OF CHILDREN WITH HEARING IMPAIRMENTS IN EDUCATION}

Children withhearing impaired are not able to meet the pace required for oral speech and, therefore, there is a need for implementation in their means of communication. The major challenge ofstudents with hearing impaired in teaching -learning-assessment process or elsewhere is their inability to speak and communicated effectively. This in turn, affects the ability interact and covey messages, (Ying, 1990)

However, as Meadow (1980), deaf child cannot communicate clearly about his/her needs, thoughts and experience not because of deprivation of sound but due to deprivation of language.

Anderson (1992) indicated that deafness by itself does not affect a person's intellect or ability to communicate effectively; such children require some form of special support.

According to Bench (1992), human communication is interpersonal, that develops early in life. It involves the sharing of thoughts, meanings and ideas between people. An act of communication usually requires a reciprocal act. Such communication skills progress naturally from a young child `s interaction with the social environment (Bench, 1992).

\section{Sign language}

Peoples with hearing impairments express their ideas using body movement instead of speech, expressing ideas by using other parts of the body: - eyes, eyebrows, cheeks, lips, tongue and shoulders in the languageare being used. Finger spelling is a special form of sign system in which each letter of the alphabet has a finger 
sign used to spell words and sentences used in conversation (Heward\&aOrlansky, 1988). Sign language is a system of symbolic communication that evolved over generation of deaf people which have been formed into natural language independent of spoken language(polizneretal , 1987) when deaf signing people with no common sign language interact, they rapidly develop a pidgin(sackea,1989) it has also been documented that deaf people who are not exposed to anural sign language develop a gesture system that does not show the properties of natural language but that may have Avery simple syntax and morphology (Padden 1989)

The emerging research on sign language has also acknowledge that sign language has highly articulated grammar and that sign language is a complex and expressive as spoken language (polizneretal, 1987).Today new technologies allow for more Sophisticated studies on sign language and on authentic conversation in sign language, however the accumulated information about sign language and manual communication cannot be compared to our broad knowledge of verbal language.

\section{Attitudinal problems}

Attitude of teachers, peers and community as a whole towards inclusion of students with hearing impairment in the regular class room can determine the development of inclusive education. (Tirusew, 2005). According to Loreman, Depillar and Harvey, (2005). Clearly stated that, irrespective of their source, our attitude clearly affect thoughts, feeling and what we do. This show us that teachers, peers and the community negative attitude towards students with hearing impairment and to inclusive schooling, can affect the progress of inclusive education, and the right of a child with impairment.

Teacher's positive attitudes towards inclusion of children with hearing impairments depend on their experience with learners who are perceived as challenging teachers training, the availability of support, class size and workload are all factors that influence teacher's attitude (UNSCO, 2005).

The Salamanca statement for action (1994) suggested that among priority area, resources must be allocated to training of mainstream teachers, and provision of resource centers for special education teachers. Thus, teachers should develop skills, knowledge and attitude in line with special needs education. Effective implementation of inclusive education program requires positive attitude of teachers towards inclusion. ReddaBarnen (1995) indicated that teacher's attitude is crucial to the success of inclusive education, because the responsibility to teach call children lies with the class teacher.

The other important point is awareness creation, according to Niemann, Greenstein, and David, (2005) creating awareness programs for teachers and school community concerning inclusive approach and disability are essential to minimize the resistance and bring about attitudinal change.

\section{Teaching Materials}

Instructional Materials can be defined in different ways depending on the purpose of the scholars. For example, Amare (1999) instructional materials are instrument with which a teacher teaches and from which students learn. From this view, we understand that instructional materials are the base for quality of education.

Mbamba (1992) defines instructional materials as "Any object or unit area of space so designed and organized deliberately to support and use teaching and learning operations". He goes on explaining that they are designed, modified and prepared to assist teaching and learning operations. According to Mbamba (1992) educational materials commonly used in educational system are:

\section{IMPORTANT OF MOTHER TONGUE AS MEDIUM OF INSTRUCTION}

In multilingual countries where settlement is mixed and many language-minorityindividuals live within the boundaries of states where the official language is differentfrom their mother tongue, many students are forced to learn in their second languagein primary school. A large number of countries have taken steps to accommodatelanguage-minority students by adopting mother tongue instruction in primary school.For instance, as a multilingual country, Ethiopia, this isalso 
the focus of thepresent study, signed into law the Education and Training Policy in 1994

(Ministryof Education, 1994). The policy document has primarily given discretion to stategovernments in Ethiopiato choose the language of instruction in primary schoolslocated in their jurisdictions. Following this discretion, many states in Ethiopia haveadopted their respective official languages (and, at times, additional minority languages) as the medium of instructionin primary schools. As a result, the mediumof instruction in primary schools in the country has increased from using Amharicas the only medium of instruction in 1990 to about 25 languages in 2007 (Seidel andMoritz, 2007). Mother tongue instruction in primary school, moreover, has a psychologicaladvantage since it facilitates adjustment between home and school and does not alienate children from their identity (Trudell, 2005). The psychological effect on students'performance plays a more important role in primary school where the need for adjustment to the school environment is of paramount importance to learn subject contents effectively.

\section{THE STATUS OF SIGN LANGUAGE IN ETHIOPIA}

In many countries, the history of sign language may be seen along with the history of deaf education and the formation of a deaf community. Ethiopia, there is no evidence, which shows the beginning of education of the deaf using sign language, The special school for the deaf in Ethiopia was started in the 1960s and 1970s by the support of missionaries and non-governmental organization from American and Europe. Mekanisa School for the Deaf, the first special school for the deaf, was established in 1962, by the Church of Christ. This school has two other branch schools "Centeria" and "Mazoria" in the Southern parts of the country. Alpha which is the second school for the deaf was established in Addis Ababa in 1967 by American Emanuel Baptist Mission. Hosanna was the third Boarding Special school for the deaf, established in 1981 by church of Mekanyesus and the fourth school for the deaf, African outreach, was opened in 1987 (Alemayehu, 2000).

After the introduction of modern education system into the country, it took a long time to give access to education for all school aged children. However, there are still various limitations to give educational access to all (including children with special needs).

According to Mamo Mengesha, Tirussew et al. (1995, 2006, cited in Ministry of Education 2006), the existing special units are situated in urban areas. It is estimated that less than $3 \%$ of school aged disabled children get access to primary education. To narrow down this gap, the Ministry of Education designed a strategy aimed at creating better educational access to children with special educational needs.

Earlier research has shown that students with special needs are marginalized in the education system. Therefore, the Ministry of Education has designed a strategy for special needs education program to guide development of an inclusive education system in 1994. The main objective of the strategy is to encourage universal primary education, including children with special needs. The strategy draws on the Ethiopian constitution that establishes the universal right to education, and the government policy goal stating that by year 2015 all school age children must have access to and complete primary education (Ministry of Education, 2006).

The first attempt was made in 1979s with the preparation of dictionary of sign language, the effort seems encouraging for before there was nothing on the education of the deaf. The first dictionary consisted of 1009 words, which were created from a collection of equivalents for Amharic and English words, Some of this words were directly translated from American Sign Language (Amharic sign language, 1979s).

In the same way, efforts were started in 1994 and completed in 1998, creating more than 2000 signs, which were compiled and disseminated to the regions some of the signs of this dictionary were gathered by deaf school teachers informally from deaf children. The preparation was organized by the institute of curriculum development and research, ministry of education (MOE).

In both cases, the owner the Ethiopian national association of the deaf has fully participated with several deaf schools and individuals. However, the preparation of both dictionaries were not without limitations; first it 
was not based on linguistic research; secondly, the numbers of signs were limited and the structure of the sign language was based on Amharic grammar or English and couldn't discover the full grammar of the language except by collecting sings. Therefore, it can be said that the existence of a sign language grammar is still unnoticed by many people, including teachers and other people working with deaf.

From this, one can imagine that the status of sing language in Ethiopia is still very low and the preparation of sign language, as a national language was not strengthened by evidence from linguistic research; there are no sign language skills among teachers, school administrators, family members and among those people working with deaf people in several places. Due to these factors, any deaf child has not acquired and develops sing language skills, as they expected and these weaknesses have several great effects on the improvement of the Status of sign language in deaf education. In addition, in the culture of the deaf that consists of traditions, manners, ideas convictions institutions, common experience that held together by their own sign language.

\section{RESEARCH DESIGN}

The descriptive survey design was employed to assess Attitude of school community towards the use of sign language for instructional purpose from physical counts and frequencies to attitudes and opinions, physical and instructional environment that are address in the objectives of the study. It is helpful to collect information directly from the population, to make use simple statistical techniques and draw valid generalization about population on the basis of representative sample. (Donald, Ary, lucy Chegerja, Cobs and AsgharRazavieh, 1990).

\section{The population of the study}

This study was conducted on Bahir Dar town which is located in the west Gojjam, Amhara Region in Yekatit 23 and Donaberber primary school and the focus was given to grade 5-8 deafstudents. Because, the researcher believes that they would better in maturity and understanding than those in the lower grade levels. The total population of this study was 220 students without hearing impairment, 13 students with hearing impairments, 23 general classroom teachers, 5 special need teachers, 2 vice principals and 2 principals of the school were the study population.

\section{Sampling technique}

Bahir Dar town consists of greater homogeneous social groupin two primary school. Being homogeneous in many respects and particularly with regard to sign language for instructional purpose at Yekatit 23 and Donaberber primary school in Bahir Dar town, selection of a fewrepresentative samples are believed to throw light up on the whole population.Using in 13students with hearing impairments, 23 general classroom teachers, 5 special need teachers, 2 vice principals and 2 principals istotal population sampling technique method use in research which involves all the respondents in the study provided the respondents' number is too small (Cohen \&Manion, 1994). Simple random sampling technique by lottery system was employed in out of 220 students without hearing impairment from this 44 students without hearing impairment was taken at Yekatit 23 and Donaber primary school in Bahir Dar town, to sample the participants who were knowledgeable enough to give the information which the researcher wanted to find out in a study.

Data collection Instruments

To collect relevant data for this study, quantitative and qualitative data collection method were used. Questionnaire, observation check list and interviews were the main data collection instruments used for the study. Each of the instruments was expected to compliment with each other and thought were essential for triangulating the data.

\section{ANALYSIS OF DATA}

Result of teachers, students, and school principals' attitude towards the use of sign language for instructional purpose.

The first purpose of this study was to investigate teachers, students and school principals' attitude towards 
the use of sign language for instructional purpose. To attain this one sample t-test was used and the results are presented in Table 2 and 3.

Table 1: Teachers Attitude toward the Use of Sign Language for Instructional Purpose

\begin{tabular}{l|l|l|l|l|l|l|}
\multicolumn{2}{l}{ Test value $=\mathbf{2 . 5}$} \\
\hline Variable & $\mathbf{N}$ & Mean & SD & t-test & Df & Sig \\
\hline Attitude & 23 & 2.85 & .57 & 2.901 & 22 & 0.008 \\
\hline
\end{tabular}

As indicated in Table 1 the results of one sample t-test shown that the mean score of teachers' attitude toward the use of sign language for instructional purpose was significantly higher than the mean test value which was 2.5 . This result shows that teachers have positive attitude toward the use of sign language for instructional purpose. Similarly, an effort was made to see students' attitude towards the use of sign language for instructional purpose. To do this again one sample t-test conducted and the results are presented in Table 2.

Table 2: Students' Attitude toward the Use of Sign Language for Instructional Purpose

\begin{tabular}{|l|l|l|l|l|l|l|}
\multicolumn{9}{l}{ Test value = 2 } \\
\hline Variable & N & Mean & SD & t-test & Df & Sig \\
\hline Attitude & 44 & 2.14 & .28 & 3.243 & 43 & 0.02 \\
\hline
\end{tabular}

As indicated in Table 3 the results of one sample t-test shown that the mean score of students' attitude toward the use of sign language for instructional purpose was significantly higher than 2 which was the mean test value. This result shows that students have positive attitude toward the use of sign language for instructional purpose. In connection to this, an attempt was made to inspect attitude towards the use of sign language for instructional purpose.

In the interviews of the special need teachers, vice principal and principals agree that though most teachers teaching in the regular class room have positive attitude towards inclusion of students with hearing impairments.

\section{Major challenges of teaching students with hearing impairment}

The second purpose of this study was to find out the major challenges. To accomplish this objective mean ranking was employed and the results are presented in Table 4.

Table 3: Challenges of Students with Hearing Impairment encountered with Regular teachers.

\begin{tabular}{|l|l|l|l|l|}
\hline No & Challenges & N & Mean & Rank \\
\hline 1 & Lack of teachers trained in special needs education & 12 & 1.6667 & 5 \\
\hline 2 & Lack of appropriate teaching learning materials & 12 & 2.0000 & 4 \\
\hline 3 & The curriculum is not designed based on the need of the learner & 12 & 1.6667 & 5 \\
\hline 4 & Lack of qualified sign language interpreters & 12 & 2.6667 & 2 \\
\hline 5 & Teachers teaching in inclusive settings lack sign language skills. & 12 & 2.7500 & 1 \\
\hline 6 & Lack of learning in sign language is a good & 12 & 2.5833 & 3 \\
\hline
\end{tabular}


As indicated in Table 3 the results of mean ranking designated that the first challenge observed was when teachers are teaching in inclusive settings lack sign language skills. The second challenge was lack of qualified sign language interpreters. The third challenge reported was lack of learning in sign language is a good. The fourth challenge was lack of appropriate teaching learning materials. The fifth challenges reported were both lack of teachers trained in special needs education and the curriculum is not designed based on the need of the learner. Correspondingly an effort was made to assess the challenges encountered by students with hearing impairment with the students without hearing impairment and the results are presented in table 4.

Table 4: Challenges of Students with Hearing Impairment encountered with Regular Students

\begin{tabular}{|l|l|l|l|l|}
\hline No & Challenges & Mean & Rank \\
\hline 1 & Lack of the student seating arrangement in class & 12 & 1.6667 & 5 \\
\hline 2 & Lack of communicates the students with hearing impairments in class & 12 & 2.3333 & 1 \\
\hline 3 & Lack of the school have suitable and enough teaching materials & 12 & 2.0000 & 3 \\
\hline 4 & Lack of using sign language inside the class room by students & 12 & 2.1667 & 2 \\
\hline 5 & Lack of participation in team work & 12 & 1.8333 & 4 \\
\hline
\end{tabular}

As indicated in table 4 the results of mean ranking shown that the first challenge students with hearing impairment encountered with regular students was lack of communicates the students with hearing impairments in class. The second challenge was lack of using sign language inside the class room by students. The third challenge was lack of the school have suitable and enough teaching materials. The fourth challenge was lack of participation in team work. The least challenge reported was lack of the student seating arrangement in class.

In the interviews of the special need teachers, vice principal and principals challenges of students with hearing impairment the first challenges was lack of qualified sign language interpreters. The second challenge was the regular teachers and regular students they lack sign language skills. The third challenge was the curriculum is not designed based on the need of the learners and the school was not appropriate teaching materials because GEQIP the $2 \%$ of the CWDS budget was not appropriately used.
The researcher also has tried to observe the situation inside and outside the classroom. Classroom observation was done in 3 class room, in grade five, seven and eight. During observation usage of sign language in the class room was good sign language interpreter in the class room theregular teacher tries to control the class room activity but the teacher and student ratio is hard to control and that is the challenge both for student and teacher. The other challenge that observed by the researcher is there is low adaptive accessible material to teach sign language as a language of instruction for deaf learner. The researcher Perceived that some scientific terms that's hard to explain in sign language because of the shortage of signs and the sign language interpreter tries to explain by finger spelling like in science subject there are many words that have no equivalent sign and that are one of the challenges. The researcher also see opportunities for student with hearing impairment some of the community is trained in sign language in continuous professional development/CPD/from special need teachers short training in regular teachers, regular 
students and its advantage for students with hearing impairments and also for school community.

\section{DISCUSSION}

The first finding of this study was to investigate teachers, students and school principals' attitude towards the use of sign language for instructional purpose. To attain this one sample t-test was used and the results showed that teachers have positive attitude towards the use of sign language for instructional purpose. According to UNSCO, 2005Teacher's positive attitudes towards inclusion of children with hearing impairments depend on their experience with learners who are perceived as challenging teachers training, the availability of support, class size and workload are all factors that influence teacher's attitude. The attitude of regular students learning together studentswith hearing impairment inclusive settings is positive toward the placement of students with hearing impairments in the regular class room. Our attitudes have a significant effect up on our thought, feelings and action. Thus, regular classroom teacher and regular student's positive attitude can move the school forward to be successful in inclusive practices.

In the interviews of the special need teachers, vice principals and principals agree that though most teachers teaching in the regular class room have positive attitude towards inclusion of students with hearing impairments. They have positive attitude of regular students towards inclusion of students with hearing impairments. They are positive attitude for students with hearing impairment in learning sign languages.

The other important point is awareness creation, according to Niemann, Greenstein, and David, (2005) creating awareness programs for teachers and school community concerning inclusive approach and disability are essential to minimize the resistance and bring about attitudinal change. From this point of view the researcher suggested that from educational bureau to school community awareness programswere increases time to time.
The second finding of this study was to find out the major challenges of students with hearing impairment that was lack of sign language skill, lack of appropriate training and lack knowledge and experience about inclusive education were the barriers in teachings students with hearing impairments in inclusive classroom. The first challenge observed was when teachers are teaching in inclusive settings lack sign language skills. The second challenge was lack of qualified sign language interpreters. The third challenge reported was lack of learning in sign language is a good. The fourth challenge was lack of appropriate teaching learning materials. The fifth challenges reported were both lack of teachers trained in special needs education and the curriculum is not designed based on the need of the learner. Correspondingly an effort was made to assess the challenges encountered by students with hearing impairment with the students without hearing impairment and the results are presented.

One of the major finding of this study was student say because of sign language gave as instructional purpose the student can focus on their learning and the enrollment of students in the school is increased from time to time. As World Bank strongly stated that Children whose first language is not used at school experience lower levels of learning and are much less likely to be able to contribute to a country's economic and intellectual development and the main goalof education is to contribute skilled man power and It's hard to get that kinds of man If they learn in their second language. (World Bank, 2006). In relation to this, "The choice of the language is a recurrent challenge in the development of quality education Speakers of mother tongues, which are not the same as the national language, are often at a considerable disadvantage in the educational system" (UNESCO, 2003).

Mother tongue instruction in primary school, moreover, has a psychologicaladvantage since it facilitates adjustment between home and school and does not alienate children from their identity (Trudell, 2005). The psychological effect on students'performance plays a more important role in primary school where the need for adjustment to the school environment is of paramount importance to learn subject contentseffectively. 
The researcher suggested that policy makers and official must give priority for child's primary language. This study also confirmed that students and teachers face challenges like mismatched teacher student ratio in the classroom and the shortage of material to teach sign language as a medium of instruction and also the classroom environment is other challenge. As Finn explained that classroom size is important in the earlier years of schooling because it is the foundation for their future education. (Finn, 1998). However, all other things being equal, smaller classes will generally be beneficial.

In inclusive classroom, if teachers do not actively support the effort to achieve integration, the placement of students with special needs in regular setting will remain problematic (Catherine, 1988 cited in Azalech, 2005). According to Antia et.al, (2002), teacher expectation can have a negative impact on the academic performance of students by communicating to students that they are not expected to fully participate in classroom activities.

In the interviews of the special need teachers and principals agree that though most teachers teaching in the regular class room have lack of sign language towards inclusion of students with hearing impairments. They lack appropriate training and neglect to pay attention for students with hearing impairments in the regular class room. Accordingly, the special need teachers and principals said that students with hearing impairments were sign language interpreters in the school was small in number and not graduated in different subject so the students' academic achievement was very low.

I observed that there is no special consideration by the classroom teachers for the hearing impaired students in planning, selection of contents, methods and strategies of teaching and learning, classroom organization and methods of assessment. The curriculum is not flexible to meet the educational needs. It is a great challenge for the hearing impaired students to be in the regular classroom.

The hearing impaired students face communication challenge with their hearing peers, the regular teachers and school administrators. From this observation; I want to investigate the social interaction and participation of hearing impaired students who are integrated in the regular classroom setting participating in different activities and out of classroom during play time, sport and extra-curricular activities.

\section{CONCLUSIONS}

The status of sing language in Ethiopia is still very low and the preparation of sign language, as a national language was not strengthened by evidence from linguistic research; there are no sign language skills among teachers, school administrators, family members and among those people working with deaf people in several places. Due to these factors, any deaf child has not acquired and develops sing language skills, as they should.

The research result also confirmed that some problem which happened like lack of skillful man power that means sign language interpreters very small and not graduated different subject, lack of willingness to teach student with hearing impairment, lack of good classroom, Lack of collaboration between special and regular classroom teachers and lack of accessible teaching material are the major challenges to practice sign language for student with hearing impairment

In conclusion, the overall picture of the results in this study indicated that the majority of deaf student an able to focus on their learning because of giving sign language as a medium of instruction.

\section{REFERENCES}

Davis, L (2006). The disability studies. $\left(2^{\text {nd }}\right)$ New York: Taylor and Francis Group.

Education and Training Policy(1994). Federal Democratic Republic of Ethiopia (1 ${ }^{\text {sted.) Addis }}$ Ababa: St George Printing Press. 
Kauff, J Hallahan (1993) Managing classroom behavior: A reflective based case based approach.

Kothari, C.R. (2004). Research methodology:Methods and techniques. India. New Age.

Jackson, S.L. (2009). Research Methods and Statistics: A Critical Thinking Approach 3rd edition. Belmont, CA: Wadsworth.Journal of languages and culture Received 8 November, 2014; Accepted 3 March, 2015

Ministry of Education (1994).Education and Training Policy, "Ministry of Education, Federal Democratic Republic of Ethiopia.

Ministry of Education.(2006).Special Needs Education Program Strategy; Emphasizing Inclusive Education to Meet the UPEC and EFA Goals. Addis Ababa.

Okombo, O. (1992). Bilingualism in the schools for the deaf. In proceedings of East African sign language seminar. Nairobi, Kenya.

P. \& Cecile McKee (2003) "Deaf children's development of English as a Second Language Research Forum, October.Pushing Science's Limits in Sign Language Lexicon.

Seidel, Katrin and Janine Moritz(2007). Changes in Ethiopia's Language and education Policy Pioneering Reforms.Proceedings Paper: 16th International Conference of Ethiopian Studies,

TirusewTefera (2005) Disability in Ethiopia: Issues, Insights and Implications.A.A.Uprinting press.

TirusewTefera (1998).Inclusion of children with Disabilities in Regular schools challenge and opportunities. The Ethiopian Journal of education Volume XIX no.1. Institute of Education Research AASU printing press.

Zehle,J.(2011). Early Intervention for Children with Special Needs: manual for students, teachers and lectures in the field of special needs education. Ethiopia; Addis Ababa University. 